\title{
ANALISIS REAKSI INVESTOR TERHADAP DEBT TO EQUITY RATIO DAN RETURN ON EQUITY RATIO
}

\author{
Agil Lestiyani 1), Irdha Yusra ${ }^{2)}$ \\ 1,2) Jurusan Manajemen, Sekolah Tinggi Ilmu Ekonomi KBP \\ ${ }^{1)}$ Email: agillezvi@gmail.com \\ ${ }^{2)}$ Email: irdhayusra@akbpstie.ac.id
}

\begin{abstract}
This study purpose to test the effect of the debt to equity ratio (DER) and the return on equity ratio (Roe) the reaction of investors (proxy using stock returns). The population used in this study is a telecommunications company listed on the Indonesia Stock Exchange (BEI) during the period 2011-2015 as 7perusahaan. From this, a sample is taken is composed of six companies. It took a period of the 2011-2015 period, using purposive sampling method. Data analysis technique used is multiple linear regression using eviews program. From the results of tests carried out showed that debt to equity ratio is statistically significant effect negativ and not on stock returns, which indicated the probability of $>0.05$ is 3.314743. Unlike the return on equity ratio is statistically insignificant negative effect on stock returns.
\end{abstract}

Keywords: Debt To Equity Ratio, Return on Equity Ratio, And Return

\section{PENDAHULUAN}

Perkembangan instrumen keuangan tidak terlepas dari perkembangan pasar modal. Dalam kegiatan pasar modal tidak terlepas dari berinvestasi saham, dimana investor memili harapan untuk memperoleh return. Tujuan investor dalam berinvestasi adalah memaksimalkan return, tanpa melupakan faktor risiko investasi yang harus dihadapinya. Return merupakan salah satu faktor yang memotivasi investor berinvestasi dan juga merupakan imbalan atas keberanian investor menanggung risiko atas investasi yang dilakukannya (Tandelilin, 2010).

Reaksi investor dapat diukur dengan menggunakan return. Return dapat digunakan sebagai alat ukur untuk mengukur keberhasilan perusahaan, return tersebut dapat berupa capital gain ataupun dividen untuk investasi pada saham dan pendapatan bunga untuk investasi pada surat hutang. Return menjadi indikator untuk meningkatkan kekayaan (wealth) para investor, termasuk didalamnya para pemegang saham. (Jogiyanto, 2010) Investor sebelum melakukan investasi pada perusahaan yang 
terdaftar di Bursa Evek Indonesia, investor melakukan analisis laporan keuangan dengan menggunakan rasio keuangan yang berkaitan dengan return perusahaan.

Debt to Equity Ratio merupakan salah satu rasio keuangan yang mengukur seberapa besar kemampuan perusahaan melunasi utang dengan modal yang dimiliki (Husnan, 2006). Debt to Equity Ratio yang tinggi menunjukkan bahwa perusahaan sangat bergantung pada pihak luar dalam mendanai kegiatan sehingga beban perusahaan juga akan meningkat. Hasil penelitian terdahulu menyatakan bahwa Debt to Equity Ratio memiliki pengaruh negatif secara signifikan terhadap harga saham. Hal ini menunjukkan bahwa Debt to Equity Ratio yang tinggi cenderung menyebabkan harga saham menurun.

Return on Equity Ratio merupakan salah satu rasio profitabilitas yang menggambarkan kemampuan perusahaan untuk menghasilkan laba bagi pemegang saham atas modal yang mereka investasikan dalam perusahaan (Tandelilin, 2001). Semakin tinggi Return On Equity Ratio maka semakin baik perusahaan tersebut di mata investor dan hal ini dapat menyebabkan harga saham perusahaan yang bersangkutan semakin naik. Hasil penelitian menunjukkan bahwa Return On Equity Ratio memiliki pengaruh positif dan signifikan terhadap harga saham, di mana meningkatnya nilai Return On Equity Ratio akan menyebabkan harga saham meningkat.

Masalah yang sering dihadapi investor dipasar modal adalah memilih perusahaan yang tepat untuk melakukan investasi agar diperoleh investasi dengan harga yang wajar dan mencerminkan investasi yang potensial. Berdasarkan perkembangan return saham Perusahaan telekomunikasi yang terdaftar di Bursa Efek Indonesia Periode 2013-2014 mengalami fluktuasi. Besarnya return saham Tertinggi dapat dilihat dari Perusahaan Telkom. Berdasarkan hal tersebut dikatakan bahwa Debt to Equity Ratio dan Return On Equity Ratio pada tahun 2013 dan 2014 menunjukkan kondisi yang konsisten dengan return saham pada perusahaan Telekomunikasi. Berbeda dengan Debt to Equity Ratio dan Return on Equity Ratio pada tahun 2015 pada perusahaan indosat dengan Return Saham. Hal ini berarti investor merespon atau bereaksi terhadap tinggi atau rendahnya nilai Debt to Equity Ratio dan Return On Equity Ratio perusahaan Telekomunikasi.

Beberapa penelitian terdahulu tentang Debt To Equity Ratio dan Return On Equity Ratio terhadap return saham salah satunya adalah penelitian yang dilakukan Natarsyah (2000) menyatakan bahwa Return On Equity Ratio dan Debt To Equity Ratio berpengaruh signifikan terhadap return saham dengan arah hubungan yang positif dan Astuti (2002) dalam penelitianya menyatakan bahwa Return On Equity Ratio berpengaruh terhadap return saham. Namun Berbeda dengan penelitian yang di lakukan oleh Ruwanti Dan Tysa (2013) dalam penelitiannya menyatakan bahwa Return 
On Invesment, Return On Equity Ratio, dan Debt To Equity Ratio secara simultan memiliki pengaruh tetapi tidak signifikan terhadap return saham.

Kumala dan Nugroho (2013), mereka menyatakan bahwa Debt To Equity Ratio berpengaruh tidak signifikan terhadap Return saham di perusahaan manufaktur yang terdaftar di BEI periode 2008-2010. Enekwe, dkk (2014), mengatakan bahwa Debt To Equity Ratio berpengaruh negatif terhadap return pada perusahaan farmasi yang di kutip di nigeria periode 2001-20

12. Utami (2015) dia menyatakan bahwa Debt to Equiti Ratio berpengaruh negatif dan tidak signifikan terhadap return saham pada perusahaan manufaktur yang terdaftar di Bursa Efek Indonesia.

Berbeda dengan penelitian yang di lakukan Rafika (2014) menyatakan bahwa Return on Equity Ratio berpengaruh tidak signifikan terhadap Erning Per Share. Azeem dan Amara (2014), Mereka mengatakan bahwa Return On Equity Ratio berpengaruh negatif terhadap return saham pada perusahaan perbankan yang terdaftar di Bursa Efek Indonesia priode 2006-2012. Susilowati (2011), Dalam penelitianya berjudul Pengaruh Rasio Profitabilitas, Likuiditas Dan Utang Terhadap Invertasi Kembali mengatakan bahwa Return on Equity Ratio berpengaruh tidak signifikan terhadap Return saham. Warrad (2015) mengatakan bahwa Return on Equity Ratio berpengaruh tidak signifikan terhadap Net Operating Cycle. Berbeda dengan penelitian yang dilakukan Wibowo dan Raharja (2014) dengan judul penelitian nya pengaruh Working Capital Turnover, Long Term Debt To Equity Ratio, Dan Return On Equity Ratio Terhadap Return Saham mengatakan bahwa Return on Equity Ratio berpengsruh tidak signifikan dan negatif terhadap Return saham.

Kumala dan Nugroho (2013), mereka menyatakan bahwa Debt To Equity Ratio berpengaruh tidak signifikan terhadap Return saham di perusahaan manufaktur yang terdaftar di BEI periode 2008-2010. Enekwe, dkk (2014), mengatakan bahwa Debt To Equity Ratio berpengaruh negatif terhadap kinerja keuangan pada perusahaan farmasi yang di kutip di nigeria periode 2001-2012. Hal ini mengidentifikasikan bahwa hubungan yang negatif antara Debt to Equity Ratio dengan Return menunjukkan apabila terjadi peningkatan pada nilai Debt To Equity Ratio perusahaan maka return mengalami penurunan. Utami (2015) dia menyatakan bahwa Debt to Equiti Ratio berpengaruh negativ dan tidak signifikan terhadap dividend paiment policy pada perusahaan manufaktur yang terdaftar di Bursa Efek Indonesia.

Dalam penelitian ini rumusan hipotesis yang diajukan sebagai berikut:

\section{H1 : Debt To Equity Ratio berpengaruh negativ dan tidak signifikan terhadap reaksi investor pada perusahaan telekomunikasi yang terdaftar di Bursa Efek Indonesia.}


Sartono (2010) menyatakan : "Return on Equity Ratio mengukur kemampuan perusahaan memperoleh laba yang tersedia bagi pemegang saham perusahaan. Rasio ini juga dipengaruhi dengan besar kecilnya hutang perusahaan apabila proporsi hutang semakin besar maka rasio ini juga akan semakin besar". Dan menurut Lukman (2009) "Return on Equity Ratio merupakan suatu pengukuran dari penghasilan (income) yang tersedia bagi para pemilik perusahaan (baik pemegang saham biasa maupun pemegang saham preferen) atas modal yang mereka investasikan di dalam perusahaan".

Rafika (2014) menyatakan bahwa Return on Equity Ratio berpengaruh tidak signifikan terhadap Erning Per Share. Azeem dan Amara (2014), Mereka mengatakan bahwa Return On Equity Ratio berpengaruh negativ terhadap return saham pada perusahaan perbankan yang terdaftar di Bursa Efek Indonesia priode 2006-2012. Hal ini mengidentifikasikan bahwa hubungan yang negatif antara Return on Equity Ratio dengan Return menunjukkan apabila terjadi peningkatan pada nilai Return on Equity Ratio perusahaan maka Return mengalami penurunan. Susilowati (2011), Dalam penelitianya berjudul Pengaruh Rasio Profitabilitas, Likuiditas Dan Utang Terhadap Invertasi Kembali mengatakan bahwa Return on Equity Ratio berpengaruh tidak signifikan terhadap Return saham. Warrad (2015) mengatakan bahwa Return on Equity Ratio berpengaruh tidak signifikan terhadap Net Operating Cycle. Berbeda dengan penelitian yang dilakukan Wibowo dan Raharja (2014) dengan judul penelitian nya pengaruh Working Capital Turnover, Long Term Debt To Equity Ratio, Dan Return On Equity Ratio Terhadap Return Saham mengatakan bahwa Return on Equity Ratio berpengsruh tidak signifikan dan negativ terhadap Return saham.

Dalam penelitian ini rumusan hipotesis yang diajukan sebagai berikut:

H2 : Return On Equity Ratio berpengaruh negativ dan tidak signifikan terhadap Reaksi Investor pada perusahaan telekomunikasi yang terdaftar di Bursa Efek Indonesia.

\section{METODE PENELITIAN}

Pada metodologi penelitian menggunakan penelitian kuantitatif karena penelitian ini bersifat menganalisa lebih lanjut laporan keuangan perusahaan manufaktur subsektor makanan dan minuman yang go publicdi BEI dan menafsirkan hasilnya dalam bentuk angka-angka. Variabel independen dalam penelitian ini adalah debt to equity ratio dan return on equity ratio sedangkan variabel dependen adalah return saham. 


\section{Populasi dan Sampel}

Perusahaan telekomunikasi yang go public dijadikan sebagai objek dalam penelitian karena perusahaan ini memiliki peranan penting dalam perkembangan teknologi komunikasi di Indonesia. Sehingga dijadikan prioritas pemerintah dalam perkembangan teknologi komunikasi nasional.

Populasi yang digunakan dalam penelitian ini adalah Perusahaan telekomunikasi yang terdatar di Bursa Efek Indonesia (BEI) selama periode 20112015 yaitu sebanyak 6 Perusahaan .

Penelitian ini mengambil sampel perusahaan telekomunikasi yang terdaftar di BEI pada tahun 2011-2015 yang diambil dengan mengunakan metode purposive sampling, dimana penelitian ini tidak dilakukan pada seluruh populasi, tetapi terfokus pada target dengan mempertimbangkan kriteria-kriteria tertentu yang telah dibuat terhadap objek yang sesuai dengan tujuan penelitian. Kriteria pemilihan sampel adalah sebagai berikut : (1 Perusahaan yang mulai terdaftar di BEI tahun 2011-2015;(2)Perusahaan yang bergerak dalam bidang telekomunikasi; (3)Perusahaan yang tidak melakukan coorporate action selama periode pengamatan; (4) Perusahaan yang memiliki laporan keuangan lengkap.(4) Mendapatkan laba bersih dari tahun 2011-2015; (6)Memiliki dan mempublikasikan informasi laporan keuangan yang lengkap; (7)Laporan keuangan disajikan dalam rupiah (Rp); (8)Perusahaan mengalami laba bersih berturut-turut dari tahun 20112015; (9)Perusahaan yang bersangkutan tidak sedang merger atau diakuisisi oleh perusahaan lain selama periode tersebut.

Setelah dilakukan analisis, maka penulis menenetapkan 6 perusahaan yang layak dijadikan sebagai sampel penelitian, yaitu : (1) Bakrie Telecom Tbk.. (2) X1 Axiata Tbk. (3) Inovisi Infracom Tbk. (4) Indosat Tbk (5) Smart freend Tbk. (6) Telekomunikasi Indonesia Tbk.

\section{Definisi Operasional Variabel Penelitian}

\begin{tabular}{|c|l|l|l|}
\hline NO & $\begin{array}{l}\text { Variabe } \\
1\end{array}$ & Definisi & Operasional \\
\hline 1 & Return & $\begin{array}{l}\text { Merupakan logaritma natural dari } \\
\text { perbandingan harga saham perioda } \\
\text { berikutnya } \\
\text { it+1 dengan perioda saat ini } \\
i^{\prime} \cdot \text { Jogiyanto, 2008). }\end{array}$ & $R_{i t}=\operatorname{Ln} \frac{P_{i t+1}}{P_{i t}}$ \\
\hline 2 & $\begin{array}{l}\text { Debt to } \\
\text { ekuity } \\
\text { ratio(D } \\
\text { ER) }\end{array}$ & $\begin{array}{l}\text { Perbandingan antara total hutang } \\
\text { dengan total ekuitas perusahaan. } \\
\text { (tandelilin, 2010). }\end{array}$ & $\begin{array}{l}\text { DER= } \\
\text { Total Debt }\end{array}$ \\
\hline
\end{tabular}




\begin{tabular}{|l|l|l|l|}
\hline 3 & $\begin{array}{l}\text { Return } \\
\text { on } \\
\text { equity } \\
\text { ratio } \\
\text { (ROE) }\end{array}$ & $\begin{array}{l}\text { Perbandingan antara laba setelah } \\
\text { pajak dengan total ekuitas } \\
\text { perusahaan. (suroto, 2012). }\end{array}$ & $\begin{array}{l}\text { ROE= } \\
\text { Net Profit After Td }\end{array}$ \\
& & & Total Equity \\
& & & \\
\hline
\end{tabular}

Sumber : Tandelilin (2010) ; Surota (20012) \& Jogiyanto(2008)

\section{Model dan Analisis Penelitian}

Rumus persamaan uji regresi berganda adalah sebagai berikut :

$$
\boldsymbol{R i t}=\alpha+\beta_{1} D E R_{i t}+\beta_{2} R O E_{i t}+e
$$

Berdasarkan model ini, dijelaskan bahwa Rit merupakan return saham individual pada periode t ; DERit merupakan debt to equity ratio pada periode $\mathrm{t}$; PERit merupakan return on equity ratio pada periode $t, \alpha$ merupakan konstanta ; $\beta$ merupakan koefisien regresi (nilai peningkatan ataupun penurunan) $; e$ merupakan Nilai Residual (Faktor Penggangu).

\section{HASIL DAN PEMBAHASAN}

Berikut hasil pengolahan data penelitian :

1. Analisis Statistika Deskriptif

Analisis statistika deskriptif mencakup nilai jumlah sampel $(\mathrm{N})$, rata-rata sampel (mean), nilai maksimum, nilai minimum serta standar deviasi $(\sigma)$ untuk masing-masing variabel.

\section{Tabel 1}

Statistika Deskriptif

\begin{tabular}{|l|c|c|c|c|c|}
\hline \multicolumn{1}{|c|}{ Variabel } & N & Maksimum & Minimun & Mean & $\begin{array}{c}\text { Standar } \\
\text { Deviasi }\end{array}$ \\
\hline Debt to equity ratio & 30 & 4.5300 & -38.5300 & -0.1327 & 7.7052 \\
\hline Return on equity ratio & 30 & 11.7300 & -1.9163 & 0.4236 & 2.2391 \\
\hline Return Saham & 30 & 44.4710 & -24.3400 & -1.0364 & 11.3619 \\
\hline
\end{tabular}

Sumber : Data diolah, Lampiran 1

Pada tabel diatas menunjukan bahwa jumlah data yang digunakan dalam penelitian ini sebannyak 30 sampel data yang diambil dari laporan tahunan publikasi perusahaan telekomunikasi yang tercatat di BEI periode 2011-2015.

Data rasio Debt To Equity Ratio tertinggi (maksimum) adalah 4.5300 dan yang terendah (minimun) adalah -38.5300. kemudian rata-rata Debt To Equity Ratio sebesar -0.1327. Sementara standar deviasi sebesar 7.7052 menunjukkan 
simpangan data yang relatif besar, karena nilainya yang lebih besar daripada nilai mean-nya yaitu sebesar 7.7052>-0.1327.

Data Return On Equity Ratio tertinggi (maksimum) adalah 11.7300 dan yang terendah (minimun) adalah -1.9163 , kemudian rata-rata Return On Equity Ratio sebesar 0.4236. Sementara standar deviasi sebesar 2.2391, menunjukkan simpangan data yang relatif besar, karena nilainya yang lebih besar daripada nilai mean-nya yaitu $2.2391>0.4236$.

Data Return Saham mempunyai tertinggi (maksimum) adalah 44.4710 dan yang terendah (minimun) adalah -24.3400 , kemudian rata-rata -1.0364 dengan nilai standar deviasi sebesar 11.3619 menunjukkan simpangan data yang relatif besar, karena nilainya yang lebih besar daripada nilai mean-nya yaitu 11.3619> -1.0364 .

\section{B. Analisis Regresi Berganda}

Alat analisis yang digunakan dalam penelitian ini adalah analisis regresi linear berganda. Sebelum model regresi di estimasi dari regresi dilakukan, maka penulis telah melakukan teknik analisis data pada penelitian ini dengan menggunakan uji stasioner, asumsi klasik yang tediri dari uji normalitas.

Melalui hasil pengujian normalitas, pengujian deskristif non parametrik disimpulkan bahwa seluruh data variabel dalam penelitian ini (debt to equity rasio, return on equity rasio, dan return saham) telah memenuhi asusmsi teori pengujian yang telah ada. Oleh karena itu, langkah selanjutnya untuk mencapai tujuan penelitian untuk memberikan hasil regresi dengan menggunakan estimasi data panel untuk hipotesis yang telah dikembangkan sebelumnya.

\section{Tabel 2}

\section{Hasil Uji Regresi Linear Berganda}

Dependent Variable: Y

Method: Least Squares

Date: 12/17/16 Time: 13:37

Sample (adjusted): 130

Included observations: 30 after adjustments

\begin{tabular}{crllr}
\hline \hline Variable & Coefficient & Std. Error & t-Statistic & Prob. \\
\hline \hline C & 3.284745 & 3.105391 & 1.057756 & 0.2995 \\
$\begin{array}{c}\text { Debt to equity ratio } \\
\begin{array}{c}\text { Return on equity } \\
\text { ratio }\end{array}\end{array}$ & -3.314743 & 1.775419 & -1.867020 & 0.0728 \\
\hline \hline $\begin{array}{l}\text { R-squared } \\
\text { Adjusted R-squared }\end{array}$ & 0.114395 & 6.109532 & -1.839283 & 0.0769 \\
\hline
\end{tabular}




\begin{tabular}{lrlr} 
S.E. of regression & 11.08123 & Akaike info criterion & 7.743022 \\
Sum squared resid & 3315.429 & Schwarz criterion & 7.883142 \\
Log likelihood & -113.1453 & Hannan-Quinn criter. & 7.787847 \\
F-statistic & 1.743815 & Durbin-Watson stat & 2.011940 \\
Prob(F-statistic) & 0.193973 & & \\
\hline \hline
\end{tabular}

Sumber : Eviews

Dari Tabel 2 dihasilkan nilai koefisien regresi untuk variabel Debt to Equity Ratio sebesar -3.314743 bertanda negatif dengan nilai probabilitas $0.0728>0.05$ yang berarti bahwa Debt to Equity Ratio mempunyai pengaruh negatif yang tidak signifikan terhadap Return Saham. Dengan demikian dapat disimpulkan hipotesis pertama ditolak.

Penelitian ini konsisten dengan hasil penelitian yang dilakukan oleh Kumala dan Nugroho (2013), mereka menyatakan bahwa Debt To Equity Ratio berpengaruh tidak signifikan terhadap Return saham di perusahaan manufaktur yang terdaftar di BEI periode 2008-2010. Enekwe, dkk (2014), mengatakan bahwa Debt To Equity Ratio berpengaruh negatif terhadap return pada perusahaan farmasi yang di kutip di nigeria periode 2001-2012. Hal ini mengidentifikasikan bahwa hubungan yang negatif antara Debt to Equity Ratio dengan Return menunjukkan apabila terjadi peningkatan pada nilai Debt To Equity Ratio perusahaan maka return mengalami penurunan.

Utami (2015) dia menyatakan bahwa Debt to Equiti Ratio berpengaruh negatif dan tidak signifikan terhadap return saham pada perusahaan manufaktur yang terdaftar di Bursa Efek Indonesia.

- Tabel 2 juga menghasilkan nilai koefisien regresi untuk variabel Return On Equity Ratio sebesar -11.23716 bertanda negatif dengan nilai probabilitas 0.0769 < 0.05 yang berarti bahwa Return On Equity Ratio mempunyai pengaruh negatif yang tidak signifikan terhadap Return Saham. Dengan demikian dapat disimpulkan hipotesis kedua ditolak.

Penelitian ini konsisten dengan hasil penelitian yang dilakukan Rafika (2014) menyatakan bahwa Return on Equity Ratio berpengaruh tidak signifikan terhadap Erning Per Share. Azeem dan Amara (2014), Mereka mengatakan bahwa Return On Equity Ratio berpengaruh negatif terhadap return saham pada perusahaan perbankan yang terdaftar di Bursa Efek Indonesia priode 2006-2012. Hal ini mengidentifikasikan bahwa hubungan yang negatif antara Return on Equity Ratio dengan Return menunjukkan apabila terjadi peningkatan pada nilai Return on Equity Ratio perusahaan maka Return mengalami penurunan.

Hasil ini di perkuat oleh penelitian Susilowati (2011), Dalam penelitianya berjudul Pengaruh Rasio Profitabilitas, Likuiditas Dan Utang Terhadap Invertasi 
Kembali mengatakan bahwa Return on Equity Ratio berpengaruh tidak signifikan terhadap Return saham. Warrad (2015) mengatakan bahwa Return on Equity Ratio berpengaruh tidak signifikan terhadap Net Operating Cycle. Berbeda dengan penelitian yang dilakukan Wibowo dan Raharja (2014) dengan judul penelitian nya pengaruh Working Capital Turnover, Long Term Debt To Equity Ratio, Dan Return On Equity Ratio Terhadap Return Saham mengatakan bahwa Return on Equity Ratio berpengsruh tidak signifikan dan negatif terhadap Return saham.

\section{KESIMPULAN}

Tujuan utama dari penelitian ini adalah untuk menguji pengaruh debt too equity ratio, return on equity ratio terhadap reaksi investor yang di proxy dengan menggunakan return saham pada perusahaan telekomunikasi yang terdaftar di Bursa Efek Indonesia

Berdasarkan hasil pengujian dan analisis data mengenai pengaruh Debt To Equity Ratio dan Return On Equity Ratio terhadap Return Saham dengan menggunakan analisis regresi linear berganda, dapat disimpulkan bahwa Debt To Equity Ratio menunjukan nilai koefisien negatif yaitu sebesar -3.314743 dengan tingkat probabilitas lebih dari 0.05 yaitu sebesar 0.0728. Untuk Return On Equity Ratio juga menunjukan nilai koefisien negatif yaitu sebesar -11.23716 dengan tingkat probabilitas kurang dari 0.05 yaitu 0.0769 .

Berdasarkan hal tersebut dapat disimpulkan bahwa Debt To Equity Ratio berpengaruh negatif dan tidak signifikan terhadap Return Saham. Sedangkan untuk Return On Equity Ratio berpengaruh negatif dan tidak signifikan terhadap Return Saham.

\section{SARAN}

Berdasarkan hasil dari penelitian dan kesimpulan di atas diharapkan melakukan penelitian lanjutan dengan memperbanyak jumlah observasi agar memperoleh hasil yang lebih akurat misalnya : periode di perpanjang, data dalam bulanan, sektor perusahaan diperluas dengan unit analisis dan sampel yang berbeda, menambahkan variabel indenpenden lain serta menggunakan periode pengamanan yang lebih panjang agar diperoleh kesimpulan yang mendukung teori dan konsep diterima secara umum. 


\section{DAFTAR PUSTAKA}

Afrianty, Meilinda. 2011. Skripsi Analisis Pengaruh Current Ratio, Total Assets Turnover, Debt to Equity Ratio, Sales dan Size Terhadap Return on Assets. Universitas Diponegoro.

Azeem, aamir dan Amara. (2014). Impact of Profitability on Quantum of Nonperforming Loans. Internal International Juornal of Multidisciplinary Consortuim. Vol.1 Issue 1. http://ijmc.rtmonline.in

Diaz, Rafika. Jufrizen. (2014). Pengaruh return on assets (ROA) dan Return On Equity (Roe) Terhadap Earning Per Share (EPS) pada perusahaan assuransi yang terdaftar di bursa efek Indonesia. Jurnal manajemen dan bisnis Vol 14 No. 02 oktober 2014. Issn 1693-7619.

Enekwe, Chinedu Innocent, Agu, Charles Ikechukwu \& Nnsgbogu, Eziedo Kenneth. (2014). The Effect of Financial Performance : Evidence of Quoted Pharmaceutical : Eviedence of Quoted Pharmaceutical Companies in Nigeria. IOSR Journal of Economics and Finance. Vol 5. PP 17-25

Hadya, R., Begawati, N., \& Yusra, I. (2017). Analisis Efektivitas Pengendalian Biaya, Perputaran Modal Kerja, dan Rentabilitas Ekonomi Menggunakan Regresi Data Panel. Jurnal Pundi, 01(03), 1-35.

Hanafi, D., \& Yusra, I. (2019). Tangibility, liquidity, growth opportunity, dan leverage: studi pada perusahaan terdaftar di Bursa Efek Indonesia. INA-Rxiv, (2001).

Komala, Lievia Angela Pinkan dan Nugroho, Paskah Ika. (2013). The effects of Probfitability Ratio, Liquidity, and Debt towards Investment Return. Journal of Business and Economics. Vol. 4, No. 11, pp. 1176-1186.

Kurniawan, A., \& Yusra, I. (2019). Apakah profitabilitas dan nilai buku berdampak terhadap return saham?: studi empiris pada perusahaan LQ45. INA-Rxiv.

Patel. (2014). Impact of Leverage on Profitability : A Study of Sabar Dairy. Internasional Multidisciplinary Research Journal. Volume1 issue3.

Putra, A. D., \& Yusra, I. (2019). Peran profitabilitas dalam memoderasi pengaruh free cash flow terhadap kebijakan dividen di Indonesia. INA-Rxiv.

Putri , Anggun dan Sampurno. 2012. Analisis Pengaruh Roa, Eps, Npm, Der Dan Pbv Terhadap Return Saham (Studi Kasus Pada Industri Real Estate And Property Yang Terdaftar Di Bursa Efek Indonesia Periode 2007-2009). 
Qusibah, V. L., \& Yusra, I. (2019). Profitabilitas , dan Ukuran Perusahaan Sebagai Faktor Penentu Leverage Perusahaan Di Indonesia. Jurnal Pundi, 03(01), 1326. https://doi.org/10.31575/jp.v3i1.125

Sari, N. N., \& Yusra, I. (2018). Analisis Likuiditas, Leverage dan Kebijakan Dividen berdasarkan Siklus Hidup Perusahaan pada Saham LQ45. INA-Rxiv.

Sugiyono. 2012. Metode Penelitian Kuantitatif Kualitatif dan R\&B. Bandung : Alfabeta.

Utami, Wikan Budi.(2015). The Effectness Of Invesments opportunity, Financing Company, Profitability, Cash, and Market To Book Value To Dividend Payment Policy. International Journal of Scientific Research and Education. Vol 3. Pages 3476-3494.

Warrad, Lina. (2015). Return on Asset an Return on Equity Effects of Net Operating Cyle : Jordanian Study. Journal OF Finance and Accounting. Vol. 6, No.14

Yusra, I. (2014). Pengaruh pengumuman perubahan peringkat obligasi terhadap perilaku investor pada perusahaan asing dan domestik. Jurnal Riset Manajemen Dan Akuntansi, 1(1).

Yusra, I. (2014). Analisis Return dan Likuiditas Saham Sebelum dan Sesudah Pengumuman Right Issue di Bursa Efek Indonesia. Jurnal Riset Manajemen Dan Akuntansi, 1(2), 150-163.

Yusra, I. (2016). Pertumbuhan Aktiva Produktif, dana Pihak Ketiga, dan Profitabilitas: Studi Empiris di BUrsa Efek Indonesia. Jurnal KBP, 03(02), 157-164.

Yusra, I., Hadya, R., Begawati, N., \& Istiqomah, L. (2019). Panel data model estimation: the effect of managerial ownership, capital structure, and company size on corporate value Panel data model estimation : the effect of managerial ownership, capital structure, and company size on corporate value. Journal of Physics: Conference Series, 1175, 1-6. https://doi.org/10.1088/17426596/1175/1/012285

Yusuf, D., \& Yusra, I. (2019). Faktor-faktor yang mempengaruhi struktur modal perusahaan. INA-Rxiv.

Zakaria. (2015). The link between ownership structure, Loan to deposit ratio, Nonperforming loan and return on equity : evidence from the Indonesian banking industry. Internasional Journal of Humanities and social Science Invention. www.ijhssi.org Volume 4 Issue 